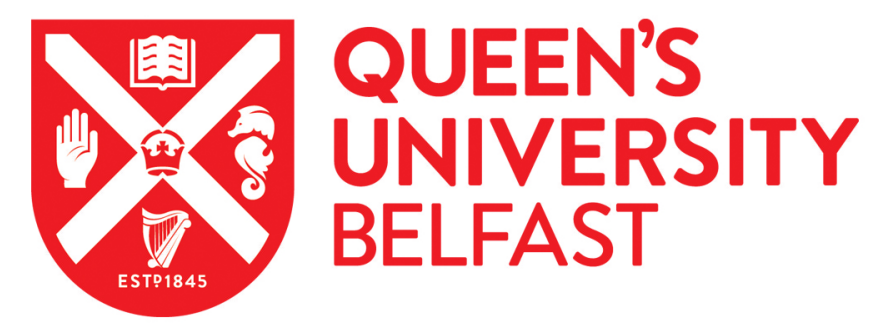

\title{
Improved survival for melanoma in northern ireland: a comparison of two 5-year periods (1984-88 and 1994-98)
}

McMullen, E. A., Kee, F., Patterson, C., Gavin, A., \& Dolan, O. M. (2004). Improved survival for melanoma in northern ireland: a comparison of two 5-year periods (1984-88 and 1994-98). British Journal of Dermatology, 151(3), 587-593.

Published in:

British Journal of Dermatology

Queen's University Belfast - Research Portal:

Link to publication record in Queen's University Belfast Research Portal

\section{General rights}

Copyright for the publications made accessible via the Queen's University Belfast Research Portal is retained by the author(s) and / or other copyright owners and it is a condition of accessing these publications that users recognise and abide by the legal requirements associated with these rights.

Take down policy

The Research Portal is Queen's institutional repository that provides access to Queen's research output. Every effort has been made to ensure that content in the Research Portal does not infringe any person's rights, or applicable UK laws. If you discover content in the Research Portal that you believe breaches copyright or violates any law, please contact openaccess@qub.ac.uk. 


\title{
Clinical and Laboratory Investigations
}

\section{Improved survival for melanoma in Northern Ireland: a comparison of two 5-year periods (1984-88 and 1994-98)}

\author{
E.A.McMULLEN, F.KEE, * C.C.PATTERSON,* A.T.GAVIN†AND O.M.DOLAN \\ The Department of Dermatology, the Royal Victoria Hospital, Belfast, Northern Ireland, U.K. \\ *The Department of Epidemiology and Public Health, Queens University, Belfast, Northern Ireland, U.K. \\ †The Northern Ireland Cancer Registry, 186 Stranmillis Road, Belfast, Northern Ireland, U.K.
}

Accepted for publication 5 February 2004

Summary Background The incidence of cutaneous malignant melanoma has been rising steadily in Caucasian populations for several decades, with a doubling time of 10-14 years. An increase in incidence of about $5 \%$ per year has been reported in most Caucasian populations since the early 1960s.

Objectives This study was designed to determine the changing incidence of primary cutaneous malignant melanoma in Northern Ireland and to examine changes in survival rates from cutaneous malignant melanoma in two 5-year periods, 1984-88 and 1994-98.

Methods One thousand three hundred and twenty-six patients with invasive primary cutaneous melanoma were included in the study.

Results The age standardized rate of melanoma rose from $4 \cdot 3$ per 100000 population per year in men and 8.6 per 100000 population per year in women to $7 \cdot 7$ and $11 \cdot 8$, respectively, per 100000 population per year in the 1994-98 period. Overall, the absolute 5-year survival for the 1984-88 period was $71 \cdot 0 \%$ [95\% confidence interval (CI) $66 \cdot 9-75 \cdot 1 \%]$ and $77 \cdot 4 \%(95 \%$ CI $73 \cdot 4-81 \cdot 4 \%)$ for the 1994-98 period. Women consistently showed better survival at all ages and within almost all categories of thickness of primary tumour. Younger patients of both sexes showed better survival rates. Conclusions When survival rates between the 1984-88 and 1994-98 periods were compared using multivariate analysis, we found that patients diagnosed in the second period had a one-third lower risk of dying than those in the earlier period. Much of this reduction was explained by changes in the number of melanomas of thin Breslow depth and ulcerated melanomas.

Key words: melanoma, Northern Ireland, survival

The incidence of cutaneous malignant melanoma has been rising steadily in Caucasian populations for several decades, with a doubling time of 10 14 years. ${ }^{1}$ An increase in incidence of about 5\% per year is reported in most Caucasian populations since the early $1960 \mathrm{~s}^{2}$ Cohort analysis shows that approximately $1: 1500$ people born in $1935,1: 600$ born in 1960, and a projected $1: 75$ born in the year 2000 will have a melanoma during their lifetime. ${ }^{3,4}$

The incidence of melanoma in Northern Ireland (population 1.6 million) doubled between the 1974-88

Correspondence: Dr Elizabeth McMullen.

E-mail: meames@doctors.org.uk and 1984-88 periods when the last analysis was performed, showing an overall rise in incidence from $3 \cdot 2$ per 100000 population to $6 \cdot 1$ per 100000 population in the later period. ${ }^{5}$ Using data held in the Northern Ireland Cancer Registry, we performed a further analysis of melanoma in Northern Ireland to compare the 1984-88 and 1994-98 periods and we report on the incidence, survival, and the patterns and trends in the anatomical and pathological characteristics of patients.

\section{Patients and methods}

The Northern Ireland Cancer Registry records details of all patients in Northern Ireland in whom a diagnosis of 
invasive primary cutaneous malignant melanoma is made. Patients are registered through pathology reports. Data were validated for completeness as follows: the five laboratories reporting melanoma cases in Northern Ireland released reports of all melanoma cases diagnosed during one randomly selected month for each year of the study period. This provided a sample of 133 of the melanoma cases within the study period. All pathology data were manually crosschecked with the data held in the Northern Ireland Cancer Registry. One hundred and thirty-one of 133 records were available. The data were therefore found to be $98.5 \%$ complete [95\% confidence interval (CI): 94.6-99.8].

Over the two 5-year study periods, 1326 patients with invasive melanomas and 478 patients with in situ melanomas were registered. In this paper we report the analysis of data from the 1326 patients with invasive melanomas.

Survival analysis was carried out using all cases of primary cutaneous malignant melanoma diagnosed in Northern Ireland during the 1984-88 and 1994-98 periods, and followed up until the 31 December 1999. Numbers under follow-up declined faster in the 199498 period, because only those diagnosed in 1994 have been followed for the full 5 years.

Information about survival and death was obtained from several sources including hospital notes, general practitioner records, hospital patient administration system enquiries, and death certificate data from the Registrar General for Northern Ireland. Complete follow-up was obtained in 1193 cases of the 1326 (90\%). Patients with incomplete follow-up were included in the survival analysis until their dates of last contact.

\section{Statistical methods}

Incidence rates were age standardized to the 1991 Northern Ireland census population by the direct method. Differences between the two study periods, 1984-88 and 1994-98 with regard to patient demographics, body site and histological features were analysed initially using Pearson's $\chi^{2}$-test and then using likelihood ratio $\chi^{2}$ tests in multidimensional contingency tables. This more complex approach enabled us to test if the nature of the association between two variables (e.g. age group and site) changed from the first to the second period, by incorporating a three-way interaction (e.g. age group $\times$ site $\times$ period) in the model. Poisson regression analysis was used to explore the changes in incidence between the periods by age group and sex.

Survival curves were calculated using the method of Kaplan and Meier. ${ }^{6}$ Initial univariate analysis using the log rank test examined the relationship of each variable individually with survival. Some variables may be associated with prognosis only because of their relationship with other variables, so multivariate analysis using the Cox proportional hazards model was used to investigate these interrelationships. The Cox model was also used to assess how much of any change in survival between the periods could be explained by changes in prognostic factors such as tumour thickness or ulceration.

\section{Results}

The incidence of melanoma rose significantly in both sexes between the two study periods. In the 1984-88 period the age standardized rate in Northern Ireland was 4.3 per 100000 population per year in men and 8.6 per 100000 population per year in women, rising to $7 \cdot 7$ and 11.8 per 100000 population per year in the 1994-98 period. The increase in incidence of melanoma in each sex was significant between the two study periods $(P<0 \cdot 001)$. The female to male ratio in the $1984-88$ period was $2 \cdot 0: 1$ falling to $1 \cdot 5: 1$ in the 1994-98 period.

Figure 1 and Tables 1 and 2 show the incidence trends for both sexes within the two time periods studied. There was an $80 \%$ rise in the age-standardized rate in males compared with a $40 \%$ rise in females (Poisson regression $\chi^{2}=6.75$, d.f. $=1, P=0.009$ for the sex $\times$ period interaction).

There was an increase in the incidence of melanoma in both males and females in most age groups.

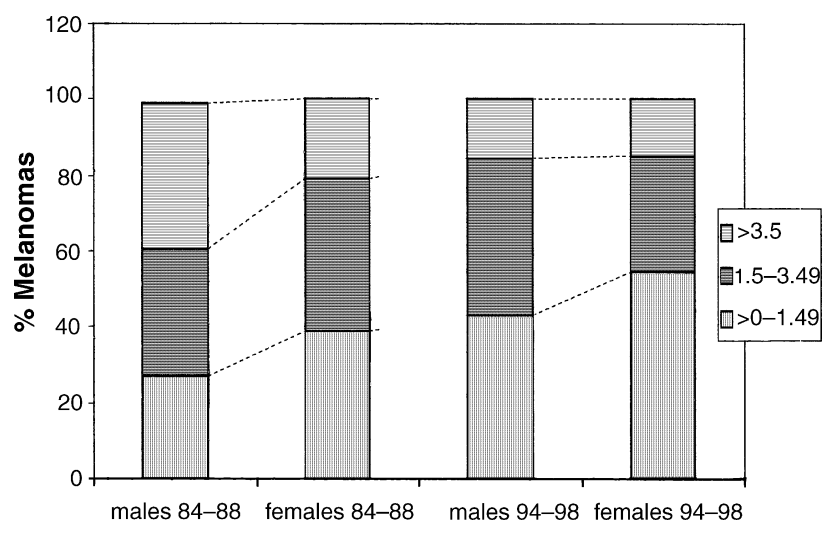

Figure 1. Melanoma age standardized rates. 
Table 1. Changes in the incidence rates of melanoma between two 5 -year periods, 1984-88 and 1994-98, in Northern Ireland

\begin{tabular}{|c|c|c|c|c|c|c|c|c|}
\hline \multirow[b]{3}{*}{ Age group } & \multicolumn{4}{|c|}{ Number of cases } & \multicolumn{4}{|c|}{ Person years (000s) } \\
\hline & \multicolumn{2}{|c|}{$1984-88$} & \multicolumn{2}{|c|}{ 1994-98 } & \multicolumn{2}{|c|}{$1984-88$} & \multicolumn{2}{|c|}{ 1994-98 } \\
\hline & M & $\mathrm{F}$ & M & $\mathrm{F}$ & M & $\mathrm{F}$ & M & F \\
\hline$<30$ & 5 & 31 & 28 & 72 & $2043 \cdot 9$ & $1921 \cdot 7$ & $1961 \cdot 7$ & $1866 \cdot 1$ \\
\hline 30-39 & 20 & 41 & 42 & 66 & $490 \cdot 0$ & $493 \cdot 0$ & $603 \cdot 1$ & $624 \cdot 7$ \\
\hline $40-49$ & 25 & 57 & 46 & 59 & $423 \cdot 0$ & $433 \cdot 1$ & $498 \cdot 5$ & $504 \cdot 5$ \\
\hline $50-59$ & 14 & 52 & 59 & 77 & $350 \cdot 7$ & $382 \cdot 2$ & $412 \cdot 5$ & $429 \cdot 7$ \\
\hline $60-69$ & 32 & 48 & 56 & 86 & $294 \cdot 7$ & $356 \cdot 9$ & $312 \cdot 6$ & $362 \cdot 8$ \\
\hline $70-79$ & 43 & 58 & 65 & 88 & $182 \cdot 6$ & $275 \cdot 1$ & $207 \cdot 4$ & $294 \cdot 0$ \\
\hline $80+$ & 16 & 39 & 30 & 71 & $54 \cdot 3$ & $127 \cdot 2$ & $72 \cdot 2$ & $167 \cdot 2$ \\
\hline Total & 155 & 326 & 326 & 519 & $3839 \cdot 2$ & $3989 \cdot 2$ & $4067 \cdot 7$ & $4249 \cdot 0$ \\
\hline
\end{tabular}

Table 2. Changes in the incidence rates of melanoma between 1984-88 and 1994-98 shown as rates per 100000

\begin{tabular}{|c|c|c|c|c|c|c|c|c|}
\hline \multirow[b]{3}{*}{ Age group } & \multicolumn{3}{|c|}{ Rates per 100000} & \multicolumn{3}{|c|}{ Rates per 100000} & \multicolumn{2}{|c|}{ Rate ratio } \\
\hline & \multicolumn{3}{|c|}{$1984-88$} & \multicolumn{3}{|c|}{ 1994-98 } & \multicolumn{2}{|c|}{ 1994-98: 1984-88 } \\
\hline & M & F & $\mathrm{F} / \mathrm{M}$ ratio & M & $\mathrm{F}$ & $\mathrm{F} / \mathrm{M}$ ratio & M & F \\
\hline$<30$ & $0 \cdot 2$ & 1.6 & $6 \cdot 6: 1$ & $1 \cdot 4$ & $3 \cdot 9$ & $2 \cdot 7: 1$ & $5 \cdot 8: 1$ & $2 \cdot 4: 1$ \\
\hline $30-39$ & $4 \cdot 1$ & $8 \cdot 2$ & $2 \cdot 0: 1$ & $7 \cdot 0$ & $10 \cdot 6$ & $1 \cdot 5: 1$ & $1 \cdot 7: 1$ & $1 \cdot 3: 1$ \\
\hline $40-49$ & $5 \cdot 9$ & $13 \cdot 2$ & $2 \cdot 2: 1$ & $9 \cdot 2$ & $11 \cdot 7$ & $1 \cdot 3: 1$ & $1 \cdot 6: 1$ & $0 \cdot 9: 1$ \\
\hline $50-59$ & $4 \cdot 0$ & $13 \cdot 6$ & $3 \cdot 4: 1$ & $14 \cdot 3$ & $17 \cdot 9$ & $1 \cdot 3: 1$ & $3 \cdot 6: 1$ & $1 \cdot 3: 1$ \\
\hline $60-69$ & $10 \cdot 9$ & $13 \cdot 4$ & $1 \cdot 2: 1$ & $17 \cdot 9$ & $23 \cdot 7$ & $1 \cdot 3: 1$ & $1 \cdot 6: 1$ & $1 \cdot 8: 1$ \\
\hline $70-79$ & $23 \cdot 5$ & $21 \cdot 1$ & $0 \cdot 9: 1$ & $31 \cdot 3$ & $29 \cdot 9$ & $1 \cdot 0: 1$ & $1 \cdot 3: 1$ & $1 \cdot 4: 1$ \\
\hline $80+$ & $29 \cdot 5$ & $30 \cdot 7$ & $1 \cdot 0: 1$ & $41 \cdot 6$ & $42 \cdot 5$ & $1 \cdot 0: 1$ & $1 \cdot 4: 1$ & $1 \cdot 4: 1$ \\
\hline Total & $4 \cdot 0$ & $8 \cdot 3$ & $2 \cdot 0: 1$ & $8 \cdot 0$ & $12 \cdot 2$ & $1 \cdot 5: 1$ & $2 \cdot 0: 1$ & $1 \cdot 5: 1$ \\
\hline
\end{tabular}

Proportionately these increases were greatest in men under 60 years (Poisson regression $\chi^{2}=7 \cdot 43$, d.f. $=1, \quad P=0.006$, for the age group $(<60$, $>60) \times$ sex $\times$ period interaction).

Table 3 summarizes the changes in melanoma characteristics that have occurred between the two time periods studied. Overall, there has been a marked increase in melanomas less than $1.5 \mathrm{~mm}$ thick between the 1984-88 and $1994-98$ periods $(P<0.0001)$. Between the two time periods the improvement in Breslow depth was most dramatic in the male sex where there has been a steep fall in melanomas at least $3.5 \mathrm{~mm}$ thick. By the 1994-98 period the overall percentage of thick melanomas is approximately $15 \%$ in both sexes (Fig. 2). In both time periods, thicker lesions were more common with advancing age $(P<0 \cdot 0001)$.

The change in melanoma thickness between periods differed between sites (multidimensional contingency table analysis likelihood ratio $\chi^{2}=23 \cdot 9$, d.f. $=8 ; P=$ 0.002 for the Breslow category $\times$ period $\times$ site interaction). All sites showed a significant improvement in thickness from the earlier to the later period with the exception of the arm, where little change in thickness was observed. Although the arm had the best distribution of Breslow thickness of any site in the earlier period, it was overtaken by the trunk and the leg in the later period. Although the foot showed significant improvement in melanoma thickness between the periods it retained its position as the site with the worst Breslow thickness distribution in both periods. Overall, in both sexes a fall in ulcerated melanomas from 38\% to $16 \%$ occurred $(P<0 \cdot 0001)$. This reduction was

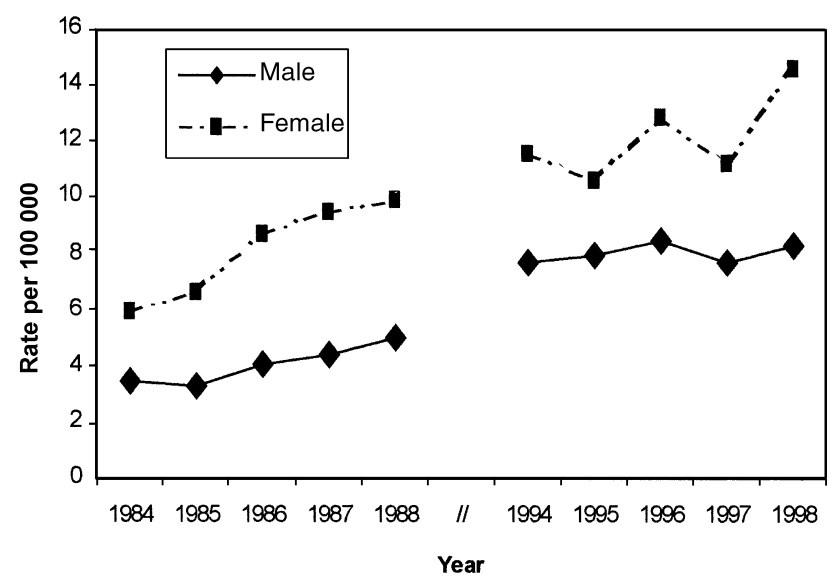

Figure 2. Melanoma Breslow Depth. 
Table 3. Showing changes in melanoma characteristics between the 1984-88 and 1994-98 periods

\begin{tabular}{|c|c|c|c|c|c|c|}
\hline \multirow[b]{3}{*}{ Characteristic } & \multicolumn{4}{|c|}{ Percentage melanomas } & \multirow[b]{3}{*}{ Male } & \multirow[b]{3}{*}{ Female } \\
\hline & \multicolumn{2}{|c|}{$1984-88$} & \multicolumn{2}{|c|}{ 1994-98 } & & \\
\hline & Male & Female & Male & Female & & \\
\hline \multicolumn{7}{|l|}{ Site } \\
\hline Head and neck & $38 \cdot 1$ & $23 \cdot 6$ & $33 \cdot 4$ & $23 \cdot 6$ & $P=0 \cdot 17$ & $P=0 \cdot 07$ \\
\hline Trunk & $22 \cdot 6$ & $8 \cdot 6$ & $30 \cdot 9$ & $8 \cdot 9$ & & \\
\hline Arm & $12 \cdot 3$ & $16 \cdot 6$ & $16 \cdot 1$ & $20 \cdot 8$ & & \\
\hline Leg & $17 \cdot 4$ & $42 \cdot 9$ & $12 \cdot 9$ & $33 \cdot 9$ & & \\
\hline Foot & $9 \cdot 7$ & $7 \cdot 7$ & $6 \cdot 3$ & $11 \cdot 5$ & & \\
\hline Perineum & $0 \cdot 0$ & $0 \cdot 6$ & $0 \cdot 3$ & $1 \cdot 4$ & & \\
\hline \multicolumn{7}{|l|}{ Type } \\
\hline SSM & $51 \cdot 0$ & $63 \cdot 4$ & $55 \cdot 3$ & $62 \cdot 6$ & $P=0.4$ & $P=0.9$ \\
\hline NMM & $11 \cdot 4$ & $12 \cdot 0$ & $14 \cdot 9$ & $13 \cdot 1$ & & \\
\hline LMM & $32 \cdot 9$ & $20 \cdot 4$ & $26 \cdot 1$ & $20 \cdot 2$ & & \\
\hline ALM & $4 \cdot 7$ & $4 \cdot 2$ & $3 \cdot 7$ & $4 \cdot 1$ & & \\
\hline \multicolumn{7}{|l|}{ Breslow depth } \\
\hline$>0-1.49 \mathrm{~mm}$ & $36 \cdot 8$ & $56 \cdot 4$ & $59 \cdot 5$ & $66 \cdot 7$ & $P<0.001$ & $P<0.01$ \\
\hline $1.5-3.49 \mathrm{~mm}$ & $24 \cdot 5$ & $22 \cdot 4$ & $24 \cdot 8$ & $18 \cdot 3$ & & \\
\hline$>3.49 \mathrm{~mm}$ & $38 \cdot 7$ & $21 \cdot 2$ & $15 \cdot 6$ & $15 \cdot 0$ & & \\
\hline \multicolumn{7}{|l|}{ Ulceration } \\
\hline Present & $45 \cdot 8$ & $35 \cdot 0$ & $17 \cdot 8$ & $16 \cdot 0$ & $P<0.001$ & $P<0.001$ \\
\hline Absent & $54 \cdot 2$ & $65 \cdot 0$ & $82 \cdot 2$ & $84 \cdot 0$ & & \\
\hline
\end{tabular}

SSM, superficial spreading melanoma; NMM, nodular metastatic melanoma; LMM, lentigo maligna melanoma; ALM, acrolentiginous melanoma.

more apparent among males (46-18\%) than females $(35-16 \%)$.

\section{Survival analysis}

The overall absolute survival rate for the first period was 5 -year survival rate $71 \cdot 0 \%$ (95\% CI: $66 \cdot 9-75 \cdot 1 \%)$ and 10-year survival rate $56 \cdot 6 \% \quad(95 \%$ CI: $52 \cdot 2-$ $61 \cdot 1 \%)$. For the second period, the 5 -year survival

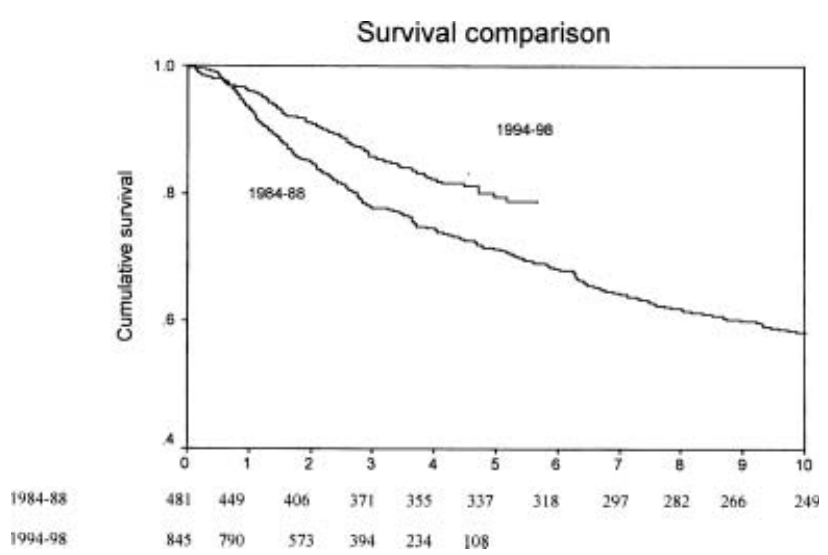

Figure 3. Comparison of survival rates between the 1984-88 and 1998-98 periods. was $77 \cdot 4 \%$ (95\% CI: $73 \cdot 4-81 \cdot 4 \%)$. Figure 3 shows survival from melanoma in both the time periods studied. The survival curves show a divergence in overall survival between the two time periods after the first year from diagnosis, which continues throughout the follow-up period.

The overall relative survival rate for the first period was 5 -year survival $84 \cdot 2 \%$ (95\% CI: $79 \cdot 2-89 \cdot 1 \%)$ and 10-year survival $78 \cdot 7 \%$ (95\% CI: $72-85 \%$ ). For the second period 5-year relative survival was $88.8 \%(95 \%$ CI: $84 \cdot 2-93 \cdot 4 \%)$.

Women consistently showed better survival at all ages and in almost all categories of thickness of the primary tumour. Younger patients of both sexes showed better survival rates, partly explained by a tendency for thinner nonulcerated primary tumours. Table 4 shows the results of the univariate and multivariate analysis, reported as relative hazards.

There is a substantial survival benefit associated with a younger age at diagnosis of melanoma. Females have a considerably reduced risk of dying compared with males in both periods, although this did not reach statistical significance in the second period.

In both periods, prognosis is worse with increasing Breslow depth, and patients with ulcerated melanomas have a greater risk of death compared with those without ulceration. Superficial spreading melanoma offers the most favourable prognosis compared with other histological types of melanoma. In the first period the multivariate analysis showed that tumours of the foot and trunk were associated with higher mortality than tumours at other sites, a finding which was also observed in the second period although it did not attain statistical significance. In the second period nodular melanoma was associated with a very high risk of death.

When survival in the two study periods was compared using multivariate analysis, we found that after allowing for age and sex, patients diagnosed with melanoma in the second period had a 30\% lower risk of dying than those in the earlier period (relative hazard 0.71, 95\% CI: 0.56-0.90). The more favourable Breslow depth and lower number of ulcerated lesions in the second period could account for much of this improved survival (relative hazard 0.88, 95\% CI: 0.69-1 13 after additional adjustment for Breslow depth and ulceration).

\section{Discussion}

We have examined the trend in melanoma incidence within and between two 5-year periods, 1984-88 and 1994-98 in the Northern Ireland population. We 
Table 4. Results of univariate and multivariate analysis using a proportional hazards model. Relative hazard and $95 \%$ confidence intervals

\begin{tabular}{|c|c|c|c|c|c|c|c|c|}
\hline \multirow[b]{3}{*}{ Variable } & \multicolumn{4}{|c|}{ Period 1984-88 } & \multicolumn{4}{|c|}{ Period 1994-98 } \\
\hline & \multicolumn{2}{|c|}{ Univariate } & \multicolumn{2}{|c|}{ Multivariate } & \multicolumn{2}{|c|}{ Univariate } & \multicolumn{2}{|c|}{ Multivariate } \\
\hline & & $P$ & & $P$ & & $P$ & & $P$ \\
\hline $\begin{array}{l}\text { Sex: } \\
\text { female vs. male }\end{array}$ & $\begin{array}{c}0.58 \\
(0 \cdot 45-0 \cdot 75)\end{array}$ & $<0.001$ & $\begin{array}{c}0.76 \\
(0 \cdot 57-1 \cdot 00)\end{array}$ & $<0.05$ & $\begin{array}{c}0 \cdot 82 \\
(0 \cdot 58-1 \cdot 16)\end{array}$ & $=0 \cdot 27$ & $\begin{array}{c}0 \cdot 74 \\
(0 \cdot 51-1 \cdot 09)\end{array}$ & $=0 \cdot 13$ \\
\hline Age (per decade) & $\begin{array}{c}1.53 \\
(1.41-1.66)\end{array}$ & $<0.001$ & $\begin{array}{c}1.43 \\
(1.29-1.59)\end{array}$ & $<0.001$ & $\begin{array}{c}1 \cdot 79 \\
(1 \cdot 59-2 \cdot 01)\end{array}$ & $<0.001$ & $\begin{array}{c}1.51 \\
(1 \cdot 32-1 \cdot 73)\end{array}$ & $<0.001$ \\
\hline \multicolumn{9}{|l|}{ Breslow depth } \\
\hline $\begin{array}{l}1.5-3 \mathrm{~mm} \text { vs. } \\
<1.49 \mathrm{~mm} \\
>3 \mathrm{~mm} \mathrm{vs} \\
<1.49 \mathrm{~mm}\end{array}$ & $\begin{array}{c}2 \cdot 64 \\
(1 \cdot 87-3 \cdot 72) \\
4 \cdot 87 \\
(3 \cdot 57-6 \cdot 66)\end{array}$ & $<0 \cdot 001$ & $\begin{array}{c}1 \cdot 63 \\
(1 \cdot 09-2 \cdot 44) \\
1 \cdot 97 \\
(1 \cdot 32-3 \cdot 08)\end{array}$ & $=0 \cdot 01$ & $\begin{array}{c}3 \cdot 54 \\
(2 \cdot 27-5 \cdot 53) \\
7 \cdot 04 \\
(4 \cdot 59,0 \cdot 8)\end{array}$ & $<0 \cdot 001$ & $\begin{array}{c}1 \cdot 57 \\
(0 \cdot 96-2 \cdot 58) \\
1 \cdot 98 \\
(1 \cdot 15-3 \cdot 41)\end{array}$ & $=0 \cdot 05$ \\
\hline $\begin{array}{l}\text { Ulceration: } \\
\text { present vs. absent } \\
\text { Tumour type }\end{array}$ & $\begin{array}{c}3 \cdot 05 \\
(2 \cdot 35,3 \cdot 96)\end{array}$ & $<0.001$ & $\begin{array}{c}1 \cdot 48 \\
(1 \cdot 07-2 \cdot 07)\end{array}$ & $=0 \cdot 02$ & $\begin{array}{c}4 \cdot 60 \\
(3 \cdot 21-6 \cdot 58)\end{array}$ & $<0.001$ & $\begin{array}{c}1 \cdot 64 \\
(1 \cdot 05-2 \cdot 55)\end{array}$ & $=0 \cdot 03$ \\
\hline LMM vs. SSM & $\begin{array}{c}1 \cdot 86 \\
(1 \cdot 25-2 \cdot 77)\end{array}$ & $<0.001$ & $\begin{array}{c}1 \cdot 12 \\
(0 \cdot 70-1 \cdot 80)\end{array}$ & $=0 \cdot 12$ & $\begin{array}{c}5 \cdot 12 \\
(2 \cdot 95-8 \cdot 87)\end{array}$ & $<0.001$ & $\begin{array}{c}2 \cdot 69 \\
(1 \cdot 31-5 \cdot 30)\end{array}$ & $=0 \cdot 001$ \\
\hline NMM vs. SSM & $\begin{array}{c}2 \cdot 71 \\
(2 \cdot 00-3 \cdot 66)\end{array}$ & & $\begin{array}{c}1 \cdot 41 \\
(0 \cdot 99-2 \cdot 00)\end{array}$ & & $\begin{array}{c}7 \cdot 68 \\
(4 \cdot 75-12 \cdot 4)\end{array}$ & & $\begin{array}{c}2 \cdot 99 \\
(1 \cdot 71-5 \cdot 23)\end{array}$ & \\
\hline ALM vs. SSM & $\begin{array}{c}3 \cdot 10 \\
(1 \cdot 79-5 \cdot 34)\end{array}$ & & $\begin{array}{c}1 \cdot 57 \\
(0 \cdot 80-3 \cdot 10)\end{array}$ & & $\begin{array}{c}2 \cdot 71 \\
(0 \cdot 94-7 \cdot 80)\end{array}$ & & $\begin{array}{c}0 \cdot 76 \\
(0 \cdot 25-2 \cdot 35)\end{array}$ & \\
\hline Undefined vs. SSM & $\begin{array}{c}2.59 \\
(1 \cdot 39-4 \cdot 84)\end{array}$ & & $\begin{array}{c}2.06 \\
(1.08-3.93)\end{array}$ & & $\begin{array}{c}3 \cdot 01 \\
(1 \cdot 59-5 \cdot 67)\end{array}$ & & $\begin{array}{c}2 \cdot 09 \\
(1 \cdot 08-4 \cdot 03)\end{array}$ & \\
\hline \multicolumn{9}{|l|}{ Tumour site } \\
\hline $\begin{array}{l}\text { Trunk vs. } \\
\text { head and neck }\end{array}$ & $\begin{array}{c}0 \cdot 86 \\
(0 \cdot 58-1 \cdot 28)\end{array}$ & $<0.001$ & $\begin{array}{c}1 \cdot 75 \\
(1 \cdot 11-2 \cdot 76)\end{array}$ & $=0 \cdot 004$ & $\begin{array}{c}0.57 \\
(0.34-0.95)\end{array}$ & $<0.001$ & $\begin{array}{c}1 \cdot 50 \\
(0 \cdot 82-2 \cdot 72)\end{array}$ & $=0 \cdot 23$ \\
\hline $\begin{array}{l}\text { Arm vs. } \\
\text { head and neck }\end{array}$ & $\begin{array}{c}0 \cdot 36 \\
(0 \cdot 23-0 \cdot 58)\end{array}$ & & $\begin{array}{c}0 \cdot 79 \\
(0 \cdot 46-1 \cdot 35)\end{array}$ & & $\begin{array}{c}0 \cdot 44 \\
(0 \cdot 25-0 \cdot 76)\end{array}$ & & $\begin{array}{c}0.95 \\
(0 \cdot 51-1 \cdot 76)\end{array}$ & \\
\hline $\begin{array}{l}\text { Leg vs. } \\
\text { head and neck }\end{array}$ & $\begin{array}{c}0 \cdot 41 \\
(0 \cdot 30-0 \cdot 58)\end{array}$ & & $\begin{array}{c}1.00 \\
(0.66-1.53)\end{array}$ & & $\begin{array}{c}0 \cdot 30 \\
(0 \cdot 17-0 \cdot 52)\end{array}$ & & $\begin{array}{c}0 \cdot 88 \\
(0 \cdot 46-1 \cdot 68)\end{array}$ & \\
\hline $\begin{array}{l}\text { Foot vs. } \\
\text { head and neck }\end{array}$ & $\begin{array}{c}1.68 \\
(1 \cdot 12-2 \cdot 52)\end{array}$ & & $\begin{array}{c}1 \cdot 85 \\
(1 \cdot 10-3 \cdot 12)\end{array}$ & & $\begin{array}{c}1 \cdot 01 \\
(0 \cdot 60-1 \cdot 72)\end{array}$ & & $\begin{array}{c}1 \cdot 68 \\
(0 \cdot 88-3 \cdot 23)\end{array}$ & \\
\hline
\end{tabular}

LMM, lentigo maligna melanoma; SSM, superficial spreading melanoma; NMM, nodular metastatic melanoma; ALM, acrolentiginous melanoma.

found an increasing incidence of melanoma characterized by a marked increase in thin melanomas. This has resulted in improvement in survival among melanoma patients in Northern Ireland. The Northern Ireland population of 1.6 million is a stable Celtic population providing an ideal setting for epidemiological study. Even though in Northern Ireland we receive less than half the yearly ultraviolet light exposure experienced by other parts of the world such as the U.S.A. and Australia (figures courtesy of the Northern Ireland Meteorological Office), the incidence of melanoma is high and continues to rise. In 1993, the 'Care in the sun' campaign was launched in Northern Ireland with the aim of increasing the awareness of the danger of sun exposure and to encourage earlier detection and referral in particular for malignant melanoma. To date there has been no assessment of the possible impact of this programme on the incidence of melanoma in Northern Ireland. The last analysis of cutaneous melanoma in Northern Ireland reported incidence figures only until 1988. The aim of this study was to perform an up-to-date epidemiological analysis of the incidence of melanoma in Northern Ireland and to compare survival figures with those previously reported for the 1970s.

We excluded all cases of melanoma in situ, because these lesions are often histologically borderline and variability of reporting of such cases is known to occur, some being reported as severely atypical or as dysplastic naevi ${ }^{7}$ and others as melanoma in situ.

A recent comparison of patient mortality comparing localized and in situ melanomas among patients registered with the Surveillance Epidemiology and End Results (SEER) registry showed no increase in excess death rate in patients diagnosed with in situ lesions compared with the general population. ${ }^{8}$ Furthermore, the inclusion of in situ melanomas might have biased our survival figures, as it is not established whether 
these lesions invariably progress to melanoma although this would seem the most likely outcome.

Among our study population, there has been a continued rise in the incidence of melanoma in both sexes between the two study periods, most marked among males. The large rise in male melanoma cases has led to a narrowing of the female to male ratio of melanomas. This is a continuation of the trend in the Northern Ireland population established since 197478. Similar findings were noted in the Scottish population, which is similar to the Irish population in terms of both skin type and lifestyle. Unlike Northern Ireland, however, the rate of melanoma in Scotland has stabilized in women. ${ }^{9}$

Despite the rise in incidence (Tables 1 and 2), this study has revealed encouraging trends with regard to patterns of Breslow depth and ulceration of melanomas in both sexes, and, given the prognostic significance of these factors, we would anticipate a favourable impact on future survival. Although the total number of melanomas continued to increase throughout the study period the percentage of less advanced lesions has risen and the percentage of advanced melanomas has fallen dramatically. This implies that the education campaign may have heightened melanoma awareness among patients and health-care workers leading to the earlier presentation of thin melanomas. A similar trend was seen in Scotland beginning in 1985 coinciding with the launch of the Scottish public education campaign in $1985 .^{10}$

This high incidence of thin melanomas and a stable or, in our case, falling incidence of thick melanomas has been reported by others. ${ }^{11}$ MacKie et al. showed a major increase in incidence of thin melanomas in both sexes, while the incidence of intermediate and thick melanomas was stable in women and increased only slightly in men. ${ }^{9}$ Melanoma reporting and pathological and clinical practice have not changed but increased awareness of melanoma and earlier presentation with suspicious lesions may have contributed to this change.

In the 1970s in Northern Ireland overall survival was very poor, in fact, it was among the worst reported at that time in the literature. ${ }^{5}$ This was thought to be due to a very high proportion of advanced melanomas. This study shows a marked improvement in overall 5year survival with 30\% lower risk of dying from melanoma in the 1994-98 period compared with the 1984-88 period. It is interesting that in this population, women had a better prognosis than men in both periods but it was only significant in the first period. This contrasts with most other reports where prognosis for melanoma is significantly worse in men than women. $^{12}$

Improvement in survival from melanoma has been seen in most countries, including Europe, the U.S.A., Australia and Scotland. In Europe, relative survival was $81 \%$ in women and $69 \%$ in men diagnosed between 1885 and $1989 .{ }^{13}$ In the U.S.A., SEER registry data indicates that 5-year relative survival among melanoma cases increased from $81 \%$ in 1975 to $89 \%$ in $1991 .^{14}$ In Scotland, the 5 -year relative survival rates improved from $64 \%$ and $78 \%$ in male and females in $1984-86$ to $82 \%$ and $91 \%$ in the $1987-89$ period. ${ }^{13}$ In Northern Ireland our relative survival rates of $77 \%$ and $87 \%$ for males and females in the $1984-88$ period, and $88 \%$ and $89 \%$ for males and females in the 1994 98 period show a particularly marked improvement in males and compare favourably with the figures elsewhere.

In Australia the peak and plateau of mortality from melanoma was thought to be partly due to earlier detection of melanomas, but a cohort-based pattern of change in mortality with decreased mortality corresponding to year of birth is consistent with a change from one generation to the next in exposure as a cause of melanoma. In the Australian population it would be consistent with a changing pattern of sun exposure beginning with those born around 1945. Public education campaigns began in Australia in the late 1950s. ${ }^{15}$

Until dangerous patterns of sunlight exposure among the Northern Ireland population decline, we are unlikely to see a fall in the number of melanomas presenting in Northern Ireland. We must continue to address the issue of primary prevention by safe behaviour in the sun. We know that almost all melanoma of the skin is caused by sunlight and that intermittent exposure of normally unexposed skin is the pattern of sun exposure associated with a propensity for development of melanoma. ${ }^{16}$ It is widely believed that sun exposure in early life is the greatest determinant of later risk of melanoma. ${ }^{17}$ People who migrate to sunnier climes earlier in life have risks similar to those people born in the destination country, while those migrating later have much lower risks. ${ }^{18}$ Case-control studies have shown little association between recent exposure and risk of melanoma. ${ }^{14}$ It is therefore important to target education campaigns towards young people.

If these studies are correct then we should begin to see a stabilizing of melanoma incidence first in young adults who have had the benefit of education cam- 
paigns since 1993 in their childhood years, and in older cohorts as time goes on. In the meantime early diagnosis remains the most important factor for improved survival from melanoma in the Northern Ireland population, where the incidence of melanoma is high and continues to rise.

\section{Acknowledgments}

The authors wish to thank the Ulster Cancer Foundation for their financial assistance with this project, and the Department of Health, Social Services and Public Safety Northern Ireland who fund the Northern Ireland Cancer Registry. We also acknowledge the previous work of Dr Pauline Pedlow who was responsible for the collection of data for the 1984-88 period.

\section{References}

1 Parkin DM, Muir CS, Whelan SL et al. Cancer Incidence in Five Continents, Vol. VI, No. 120. Lyon: International Agency for Research on Cancer, 1992; 952.

2 Muir CS, Nectoux J, Magnus K. Trend in cancer incidence. Causes and practical implications. In: Time Trends: Malignant Melanoma of the Skin (Muir CS, Nectoux J, Magnus K, eds). Washington DC: Hemisphere Publishing, 1982: 365-85.

3 Friedman RJ, Rigel DS, Silverman MK. Malignant melanoma in the 1990s: the continued importance of early detection and self-examination of the skin. CA Cancer J Clin 1991; 41: 201-26.

4 Sober AJ. Cutaneous melanoma; opportunity for cure. J Am Cancer Soc 1991; 41: 197-9.
5 Pedlow PJ, Walsh MY, Patterson CC et al. Cutaneous malignant melanoma in Northern Ireland. Br J Cancer 1997; 76: 124-6.

6 Kaplan EL, Meier P. Non parametric estimation from incomplete observations. J Am Stat Assoc 1958; 53: 457-81.

7 Newton Bishop JA. The atypical naevus: a clinician's view-point. Prog Pathol 1996; 23: 179-89.

8 Harrison RA, Soong S, Lee JAH. Comparative mortality of patients diagnosed with localised and in situ melanomas. J Insur Med 1998; 30: 157-68.

9 MacKie RM, Hole D, Hunter JAA et al. Cutaneous malignant melanoma in Scotland: incidence, survival, and mortality. Br Med J 1997; 315: 1117-21.

10 MacKie RM. Secondary prevention of cutaneous malignant melanoma. Melanoma Res 1997; 7: 151-4.

11 Lipsker D, Hedelin G, Heid E et al. Striking increase of thin melanomas contrasts with stable incidence of thick melanomas. Arch Dermatol 1999; 135: 1451-6.

12 Miller JG, MacNeil S. Gender and cutaneous melanoma. $\mathrm{Br} \mathrm{J}$ Dermatol 1996; 136: 657-65.

13 Smith JAE, Whatley PM, Redburn JC et al. Improving survival in melanoma patients in Europe since 1978. Eur J Cancer 1998; 34: 2197-203.

14 Ries LAG, Kosary CL, Hankey BF et al. Cancer Statistics Review: 1973-1996. Bethesda MD: National Cancer Institute 1999.

15 Giles GG, Armstrong BK, Burton RC et al. Has mortality stopped rising in Australia? Analysis of trends between 1931 and 1994. Br Med J 1996; 312: 1121-5.

16 International Agency for Research on Cancer. Ultraviolet Radiation. Lyon: IARC Monographs on the Evaluation of Carcinogenic Risks to Humans, 1992.

17 Elwood JM, Jopson J. Melanoma and sun exposure; an overview of published studies. Int J Cancer 1997; 7: 151-4.

18 Mack TM, Floderus B. Malignant melanoma risk by nativity, place of residence at diagnosis, and age at migration. Cancer Causes Control 1999; 2: 401-11. 